\title{
Economic analysis and environmental impact assessment of three different fermentation processes for fructooligosaccharides production
}

\author{
Solange I. Mussatto ${ }^{\mathrm{a}, *}$, Luís M. Aguiar ${ }^{\mathrm{b}}$, Mariana I. Marinha ${ }^{\mathrm{b}}$, Rita C. Jorge ${ }^{\mathrm{b}}$, Eugénio C. Ferreira ${ }^{\mathrm{b}}$ \\ ${ }^{a}$ Department of Biotechnology, Delft University of Technology, Julianalaan 67, 2628 BC Delft, The Netherlands \\ ${ }^{\mathrm{b}}$ CEB - Centre of Biological Engineering, University of Minho, Campus de Gualtar, 4710-057 Braga, Portugal
}

\section{H I G H L I G H T S}

- Three different fermentation processes for the production of FOS were studied.

- Free or immobilized cells fermentation and solid-state fermentation (SSF).

- The economic aspects and environmental impact of the processes were compared.

- SSF was the most attractive process in both economic and environmental aspects.

\section{A R T I C L E I N F O}

Article history:

Received 18 July 2015

Received in revised form 11 September 2015

Accepted 13 September 2015

Available online 26 September 2015

\section{Keywords:}

Fructooligosaccharides

Solid-state fermentation

Coffee silverskin

Economic analysis

Environmental impact

\begin{abstract}
A B S T R A C T
Three different fermentation processes for the production of fructooligosaccharides (FOS) were evaluated and compared in terms of economic aspects and environmental impact. The processes included: submerged fermentation of sucrose solution by Aspergillus japonicus using free cells or using the cells immobilized in corn cobs, and solid-state fermentation (SSF) using coffee silverskin as support material and nutrient source. The scale-up was designed using data obtained at laboratory scale and considering an annual productivity goal of $200 \mathrm{t}$. SSF was the most attractive process in both economic and environmental aspects since it is able to generate FOS with higher annual productivity (232.6 t) and purity (98.6\%) than the other processes; reaches the highest annual profit (6.55 M€); presents the lowest payback time ( 2.27 years); and is more favourable environmentally causing a lower carbon footprint $(0.728 \mathrm{~kg} / \mathrm{kg}$, expressed in mass of $\mathrm{CO}_{2}$ equivalent per mass of FOS) and the lowest wastewater generation.
\end{abstract}

(c) 2015 Elsevier Ltd. All rights reserved.

\section{Introduction}

Fructooligosaccharides (FOS) are fructose oligomers with interesting properties such as low caloric value, non-carcinogenicity and effects in decreasing the levels of phospholipids, triglycerides and cholesterol. They also help gut absorption of calcium and magnesium and stimulate the bifidobacteria growth in the human colon (Mussatto et al., 2009; Mussatto and Teixeira, 2010). Due to these important properties, FOS has attracted an increased interest mainly as ingredients for food applications, and their demand has risen rapidly (about $15 \%$ per year) in the last years. As a consequence of this, establishing a sustainable and economically viable industrial process for the production of FOS with high yields and productivities has been strongly desired.

\footnotetext{
* Corresponding author. Tel.: +31 (0) 15278 8789; fax: +31 (0) 152782355.

E-mail addresses: S.I.Mussatto@tudelft.nl, solangemussatto@hotmail.com (S.I. Mussatto).
}

Even though most investigations on FOS production are based on submerged fermentation systems, recent studies have suggested solid-state fermentation (SSF) as an interesting alternative to produce these oligosaccharides with higher productivities and yields than those currently obtained on industrial scale (Mussatto and Teixeira, 2010; Mussatto et al., 2013a; Mitchell et al., 2006). A recent study reported by Mussatto and coworkers, in which coffee silverskin was used as solid support and nutrient source in SSF for FOS production, is a good example of that (Mussatto et al., 2013a). This study reports much higher FOS productivity $(8.05 \mathrm{~g} / \mathrm{L} \mathrm{h})$ by SSF than by submerged fermentation with free $(5.36 \mathrm{~g} / \mathrm{L} \mathrm{h})$ or immobilized cells $(6.61 \mathrm{~g} / \mathrm{L} \mathrm{h})$ (Mussatto et al., 2009). SSF is also attractive because low capital costs and low demand of water are required, generating less wastewater as a consequence (Martins et al., 2011). Despite all the positive aspects and encouraging results already obtained, SSF is a process not yet implemented on industrial scale and attention must be paid to the design of the fermenters and to physicochemical parameters of the process (Mitchell et al., 2006). 
To be implemented on an industrial scale, a process must be profitable and sustainable. In this sense, the experimental point of view may serve as a basis for simulation procedures in order to verify the economic and environmental assessments (Mussatto et al., 2013b). The aim of this work was to perform an economic and environmental analysis of three different processes for FOS production: FCF (submerged fermentation using free cells), ICF (submerged fermentation using immobilized cells) and SSF. These processes were simulated using the software SuperPro Designer $v 8.5$ and an annual productivity goal of $200 \mathrm{t}$ was considered. Data obtained in previous studies at laboratory scale (Mussatto et al., 2009, 2013a) were used for the simulation, including productivities, product concentrations, yields, and other important thermophysical data. Mass and energy integration concepts were addressed in the development of these processes.

\section{Methods}

Process design, cost estimation and the project's economic evaluation was developed using the SuperPro Designer ${ }^{\circledR} v 8.5$ software package (Intelligen Inc., Scotch Plains, NJ). The Waste Reduction Algorithm Graphical User Interface v1.0, or WAR GUI, a program developed by the U.S. Environmental Protection Agency (EPA), was used for the environmental impact assessment.

The stoichiometry of the reactions was determined with the Solver add-on from the MS Excel 2013 tool from Microsoft Office 2013 where the reactants and reaction products were established based on laboratory scale results (Mussatto et al., 2009, 2013a). The stoichiometric coefficients were determined, for each case, establishing the mass balance with this tool. Solver adjusted the coefficient values - the decision variable - so that the mass balance between products and reactants equalled zero (the constraint cell). Atomic restrictions were not imposed since some molecular formulas are unknown, such as for coffee silverskin or yeast extract. The concentrations and yield values presented in the mentioned studies were used as initial data to calculate the specific yields (GF2, GF3 and GF4), glucose and fructose yields and to calculate the substrate consumption in each case. The known and calculated coefficients were fixed, namely sucrose, glucose, fructose, and FOS (GF2, GF3 and GF4) - in FCF and ICF processes - and sucrose, and FOS in the SSF process. The remaining coefficients were then fitted, resulting in the following stoichiometric reaction equations for the FCF (1), ICF (2) and SSF (3) processes, where "S" stands for sucrose, "YE" yeast extract, "Nu" nutrients, "B" biomass, "G" glucose, "F" fructose and "Su" support (coffee silverskin, because it is also a nutritional source in the SSF process) (Mussatto et al., 2013a).

$$
\begin{aligned}
\mathrm{S}+0.93 \mathrm{O}_{2}+0.09 \mathrm{YE}+0.79 \mathrm{Nu} \rightarrow & 1.05 \mathrm{~B}+1.09 \mathrm{CO}_{2}+0.45 \mathrm{GF} 2 \\
& +0.16 \mathrm{GF} 3+0.03 \mathrm{GF} 4+0.20 \mathrm{G} \\
& +0.03 \mathrm{~F}+1.04 \mathrm{H}_{2} \mathrm{O}
\end{aligned}
$$

$$
\begin{aligned}
\mathrm{S}+1.50 \mathrm{O}_{2}+0.07 \mathrm{YE}+0.78 \mathrm{Nu} \rightarrow & 0.51 \mathrm{~B}+0.53 \mathrm{CO}_{2}+0.52 \mathrm{GF} 2 \\
& +0.18 \mathrm{GF} 3+0.03 \mathrm{GF} 4+0.23 \mathrm{G} \\
& +0.03 \mathrm{~F}+0.51 \mathrm{H}_{2} \mathrm{O}
\end{aligned}
$$

$\mathrm{S}+1.33 \mathrm{O}_{2}+1.90 \mathrm{Su} \rightarrow 0.78 \mathrm{~B}+0.64 \mathrm{CO}_{2}+0.58 \mathrm{GF} 2+0.29 \mathrm{GF} 3$

$$
+0.16 \mathrm{G}+0.03 \mathrm{~F}+0.50 \mathrm{H}_{2} \mathrm{O}
$$

Table 1 shows the nutrients, sucrose, yeast extract and immobilization carrier (corn cobs in the ICF case and coffee silverskin in the SSF case) masses that were fed to each system following stoichiometric calculations. The carbon balance of each culture is shown in Table 2 . The carbon mass, $m_{\mathrm{c}}$, was determined using the Eq. (4), where $m_{\text {comp }}(\mathrm{kg})$ is the component mass (e.g. sucrose,

\begin{tabular}{|c|c|c|c|c|c|c|}
\hline & \multicolumn{4}{|c|}{ Mass values (kg) } & \multicolumn{2}{|c|}{$\begin{array}{l}\text { Productivity and } \\
\text { Purity }\end{array}$} \\
\hline & $S$ & $\mathrm{Nu}$ & YE & I & $P_{\mathrm{a}}(\mathrm{t})$ & $X_{\mathrm{FOS}}(\%)$ \\
\hline FCF & 1116.0 & 258.3 & 129.3 & - & 148.9 & 96.6 \\
\hline ICF & 972.0 & 222.3 & 87.8 & 48.6 & 158.3 & 98.4 \\
\hline SSF & 993.6 & - & - & 79.6 & 232.6 & 98.6 \\
\hline
\end{tabular}

Table 1

Mass values of sucrose $(\mathrm{S})$, nutrients $(\mathrm{Nu})$, yeast extract $(\mathrm{YE})$ and immobilization carrier (I) - corn cobs in the ICF case and coffee silverskin in the SSF case - to be fed to each system after stoichiometric calculations. Values of annual productivity $\left(P_{\mathrm{a}}\right)$ and purity $\left(X_{\mathrm{FOS}}\right)$ expressed as weight percentage of FOS, for each fermentation process.

FCF: submerged fermentation of sucrose solution by Aspergillus japonicus using free cells; ICF: submerged fermentation of sucrose solution by A. japonicus using immobilized cells; SSF: solid-state fermentation.

glucose, GF2...), $M_{\text {comp }}$ is its molar mass ( $\left.\mathrm{g} / \mathrm{mol}\right), M_{\mathrm{C}}$ is the carbon molar mass and $N_{C}$ is the number of $C$ atoms present in $1 \mathrm{~mol}$ of the component.

$m_{\mathrm{C}}=\frac{m_{\text {comp }}}{M_{\text {comp }}} M_{\mathrm{C}} N_{\mathrm{C}}$

The difference between the total carbon mass as a reactant and its total mass as a product is explained by the fact that the reactants $\mathrm{YE}, \mathrm{Nu}$ and $\mathrm{Su}$ possess carbon content in unknown proportions. In this way, the resulting difference $(\mathrm{kg})$ represents the total carbon mass present in these reactants fed to the system. For the FCF case: $m_{\mathrm{C}(\mathrm{YE})}+m_{\mathrm{C}(\mathrm{Nu})}=160.24 \mathrm{~kg}$; for the ICF process: $m_{\mathrm{C}(\mathrm{YE})}+m_{\mathrm{C}(\mathrm{Nu})}=175.38 \mathrm{~kg}$; and for the SSF: $m_{\mathrm{C}(\mathrm{Su})}=269.44 \mathrm{~kg}$; where $m_{\mathrm{C}(i)}$ is the mass of carbon present in the component $i$.

\subsection{Process model description}

The three fermentation processes (FCF, ICF and SSF) have a similar sequence of operations including the FOS synthesis, some purification steps, concentration and sterilization (high temperature sterilization is not recommended to avoid colouring the reaction products (Monsan and Ouarné, 2009). The processes were organized by sections (group of unit procedures) and they all operated with batch fermentations, in order to simulate the conditions of the studies in which this work was based on, during $24 \mathrm{~h}$ a day and 330 days per year. The process flowcharts are represented in Figs. 1-3 for the FCF, ICF and SSF processes, respectively.

\subsubsection{Free cells fermentation (FCF)}

In the FCF process the medium preparation is made in a $6.2 \mathrm{~m}^{3}$ agitated tank that is fed by two streams: the 'Nutrients' stream composed by sucrose, yeast extract and micronutrients, according to stoichiometric calculations (see Table 1) - and the 'Water' stream in which its amount depends on the desired concentration for the solution. The outlet stream, 'Medium' is sterilized with $121^{\circ} \mathrm{C}$ and sent to an agitated fermenter of $5.4 \mathrm{~m}^{3}$ that also receives an aeration stream, expressed in gas volume per unit of liquid volume $(V / V)$ per minute, of $0.5 \mathrm{~min}^{-1}$. The fermentation reaction occurs during $24 \mathrm{~h}$, at $28^{\circ} \mathrm{C}$ (Mussatto et al., 2009). Two outlet streams exit the fermenter, the 'Emissions' stream, regarding the gas emissions, and the 'Fermented broth' stream. A sequence of washing steps is performed to ready the fermenter for the next cycle - acid washing with $\mathrm{H}_{3} \mathrm{PO}_{4} 20 \%(w / w)$, water washing and alkali washing with $\mathrm{NaOH} 0.5 \mathrm{~mol} / \mathrm{L}$.

The fermented broth is then centrifuged during $6 \mathrm{~h}$, where the biomass is separated from the broth $-2.7 \%(w / w)$ of FOS are lost in this process. The 'Concentrate' stream is sent to the organic waste storage tank and the 'Supernatant' stream is taken to the ultrafiltration stage to separate residual biomass and yeast extract that was not consumed - an efficiency of $97.3 \%(w / w)$ of FOS recovery is 
Table 2

Carbon mass balance for the FCF, ICF and SSF processes. $C_{\mathrm{IN}}$ : carbon mass in; $C_{\mathrm{OUT}}$ : carbon mass out; $C_{\mathrm{Net}}$ : carbon mass net.

\begin{tabular}{|c|c|c|c|c|c|c|c|c|c|c|}
\hline \multirow[t]{2}{*}{ Component } & \multirow[t]{2}{*}{ Molecular formula } & \multicolumn{3}{|l|}{ FCF } & \multicolumn{3}{|l|}{ ICF } & \multicolumn{3}{|l|}{ SSF } \\
\hline & & $\frac{C_{\mathrm{IN}}}{\mathrm{kg}}$ & $\frac{C_{\text {ouT }}}{k g}$ & $\frac{C_{\mathrm{Net}}}{\mathrm{kg}}$ & $\frac{C_{\mathrm{IN}}}{\mathrm{kg}}$ & $\frac{C_{\text {out }}}{k g}$ & $\frac{C_{\mathrm{Net}}}{\mathrm{kg}}$ & $\frac{C_{\mathrm{IN}}}{\mathrm{kg}}$ & $\frac{C_{\text {OUT }}}{k g}$ & $\frac{C_{\mathrm{Net}}}{\mathrm{kg}}$ \\
\hline$S$ & $\mathrm{C}_{12} \mathrm{H}_{22} \mathrm{O}_{11}$ & 469.87 & 23.52 & & 409.25 & 4.24 & & 418.34 & 8.37 & \\
\hline B & $\mathrm{CH}_{1.8} \mathrm{O}_{0.5} \mathrm{~N}_{0.2}$ & 0 & 39.10 & & 0 & 17.34 & & 0 & 26.70 & \\
\hline $\mathrm{Nu}$ & - & - & - & & - & - & & - & - & \\
\hline YE & - & - & - & & - & - & & - & - & \\
\hline $\mathrm{Su}$ & - & - & - & & - & - & & - & - & \\
\hline $\mathrm{CO} 2$ & $\mathrm{CO}_{2}$ & 0 & 40.59 & & 0 & 17.72 & & 0 & 21.87 & \\
\hline GF2 & $\mathrm{C}_{18} \mathrm{H}_{32} \mathrm{O}_{16}$ & 0 & 304.57 & & 0 & 315.12 & & 0 & 358.46 & \\
\hline GF3 & $\mathrm{C}_{24} \mathrm{H}_{42} \mathrm{O}_{21}$ & 0 & 141.40 & & 0 & 146.34 & & 0 & 235.41 & \\
\hline GF4 & $\mathrm{C}_{30} \mathrm{H}_{52} \mathrm{O}_{27}$ & 0 & 29.79 & & 0 & 30.88 & & 0 & - & \\
\hline G & $\mathrm{C}_{6} \mathrm{H}_{12} \mathrm{O}_{6}$ & 0 & 45.37 & & 0 & 46.95 & & 0 & 31.81 & \\
\hline \multirow[t]{2}{*}{$\mathrm{F}$} & $\mathrm{C}_{6} \mathrm{H}_{12} \mathrm{O}_{6}$ & 0 & 5.74 & & 0 & 5.95 & & 0 & 5.12 & \\
\hline & & & & 160.21 & & & 175.38 & & & 269.40 \\
\hline
\end{tabular}

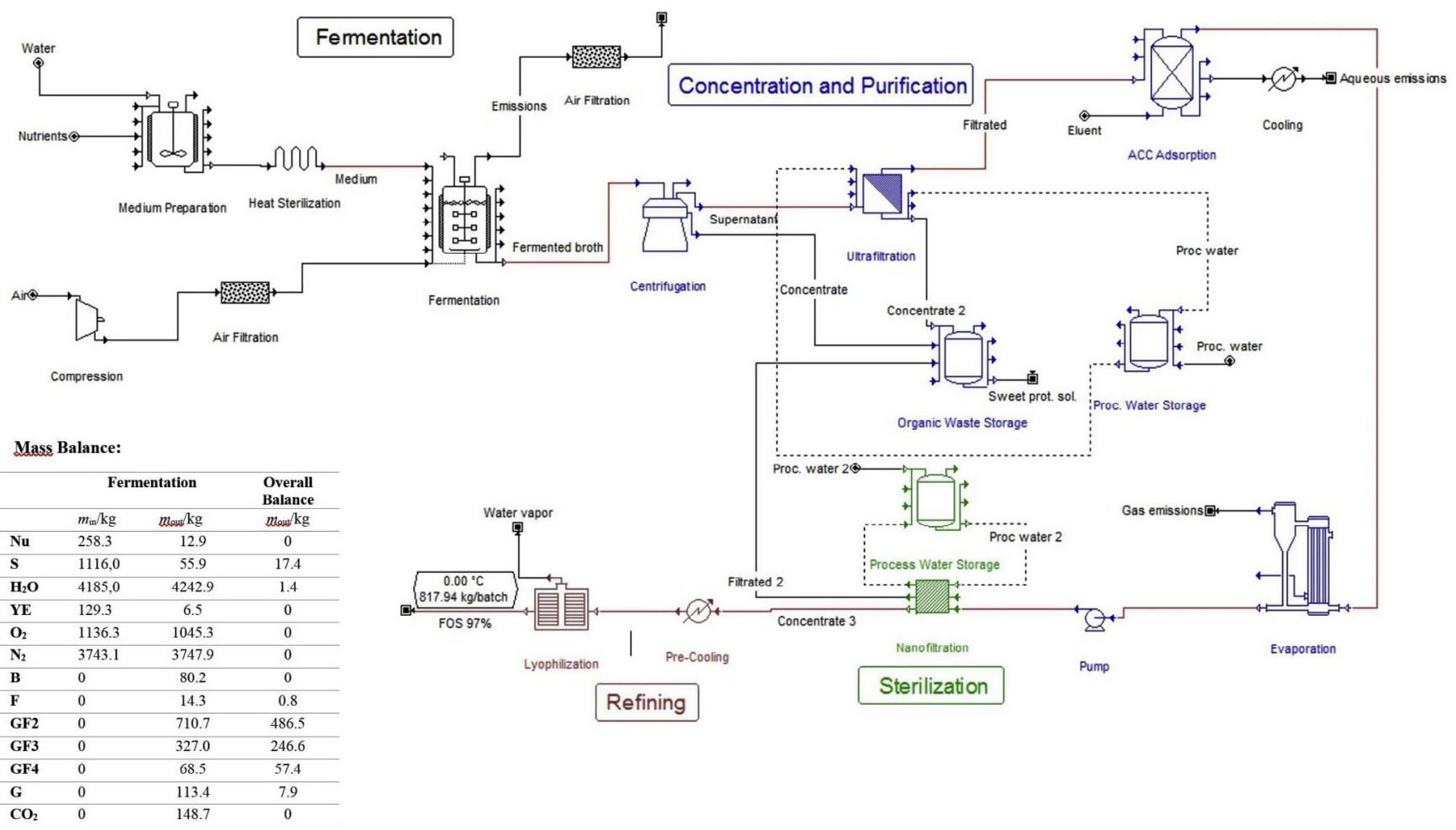

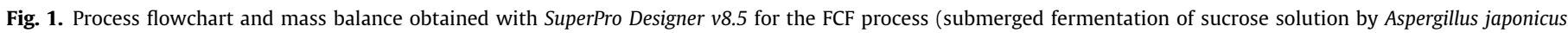
using free cells). Nu: nutrients; S: sucrose; YE: yeast extract; B: biomass; F: fructose; G: glucose; GF2, GF3, GF4: FOS.

obtained. The ultrafiltration membrane is replaced each $1000 \mathrm{~h}$ of operation time. The 'Filtrate' stream goes to the activated charcoal column adsorption (ACC Adsorption). This method of FOS purification was tested by Gonçalves (2011) and it was considered a good and economical operation for FOS purification - an efficiency of $88.4 \%(w / w)$ of FOS recovery was set based on this study $(86.9 \%$ $(w / w)$ for GF2 and $90.4 \%(w / w)$ for GF3). In this operation, ethanol $50 \%(V / V)$ is used as eluent. The ACC Adsorption is the step in which a greater amount of monosaccharides (fructose and glucose) is separated from the main stream due to their shorter size comparatively to the FOS size (Gonçalves, 2011; Nobre et al., 2012). Two outlet streams leave this stage. The 'Aqueous emissions' stream, corresponding to the liquid phase composed by the non-adsorbed sugars, is the subject of a cooling operation (from $39.9{ }^{\circ} \mathrm{C}$ until $25.0^{\circ} \mathrm{C}$ ) for wastewater discharge purposes. Subsequently the main stream is conducted to an evaporation operation where the ethanol is removed and goes to the 'Gas emissions' stream. In order to avoid colouring the reaction products, the evaporation is processed at
0.06 bar, allowing for a lower evaporation temperature. After this step, a pump is used for pressure stabilization ( 1.013 bar) and the main stream goes to the nanofiltration stage where the biggest sugars (FOS) are concentrated - the recovery efficiency of FOS equals $87.2 \%(w / w)$. The filtered stream (composed by fructose, glucose, sucrose, water and FOS) goes to the organic waste storage tank whereas the concentrated stream follows to the last section. In the refining section, the concentrated stream is pre-cooled, optimizing energy consumption in the following step, the lyophilisation. At this stage, the final product suffers a transition from the liquid state to the solid state where it is frozen and dehydrated by sublimation, to satisfy both areas of the market, the industry and the common consumer.

\subsubsection{Immobilized cells fermentation (ICF)}

In the ICF process there is an additional section comparatively to the FCF one, namely the preparation of the immobilization 


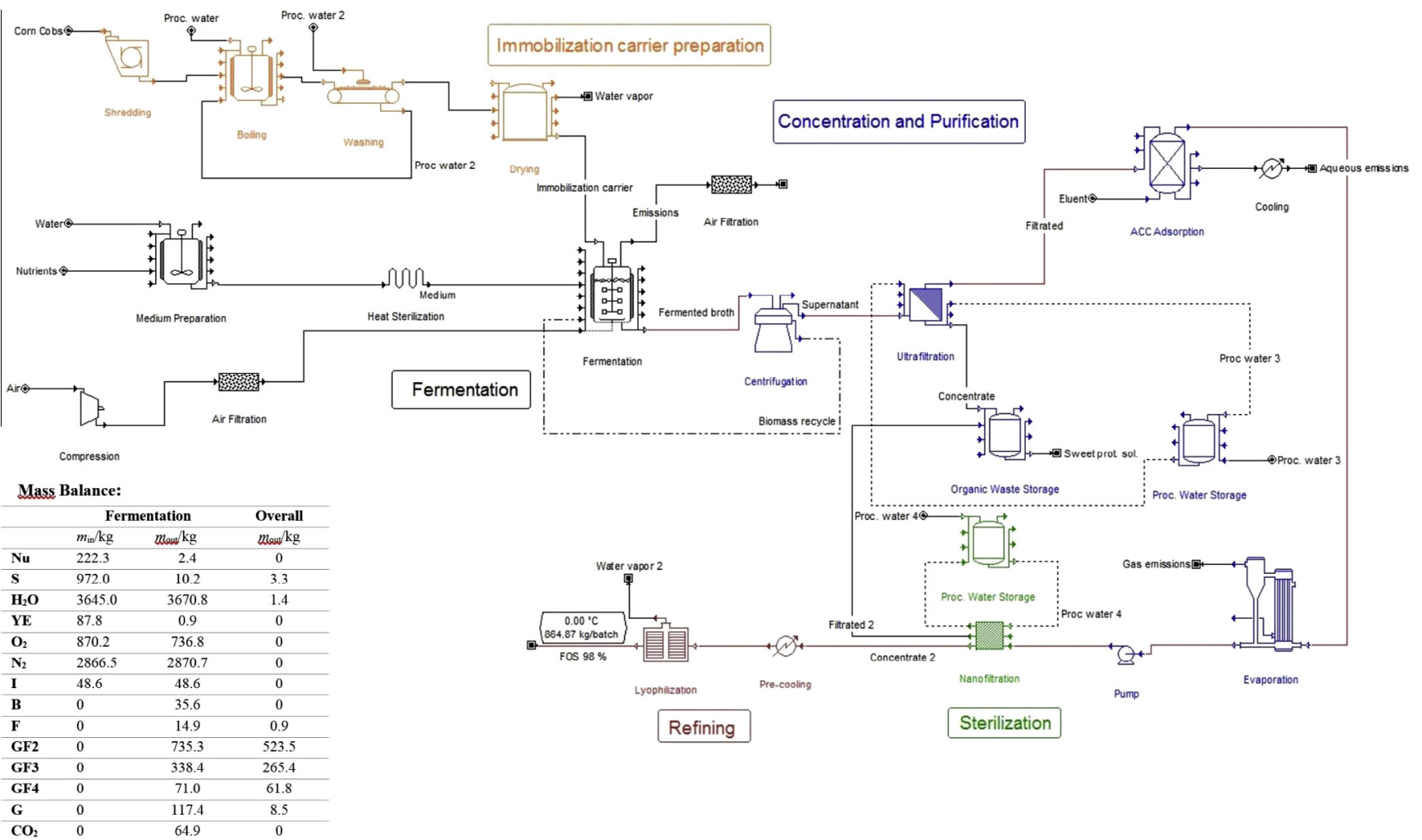

Fig. 2. Process flowchart and mass balance obtained with SuperPro Designer $v 8.5$ for the ICF process (submerged fermentation of sucrose solution by Aspergillus japonicus using the cells immobilized in corn cobs). Nu: nutrients; S: sucrose; YE: yeast extract; B: biomass; F: fructose; G: glucose; GF2, GF3, GF4: FOS; I: immobilization carrier (corn cobs).

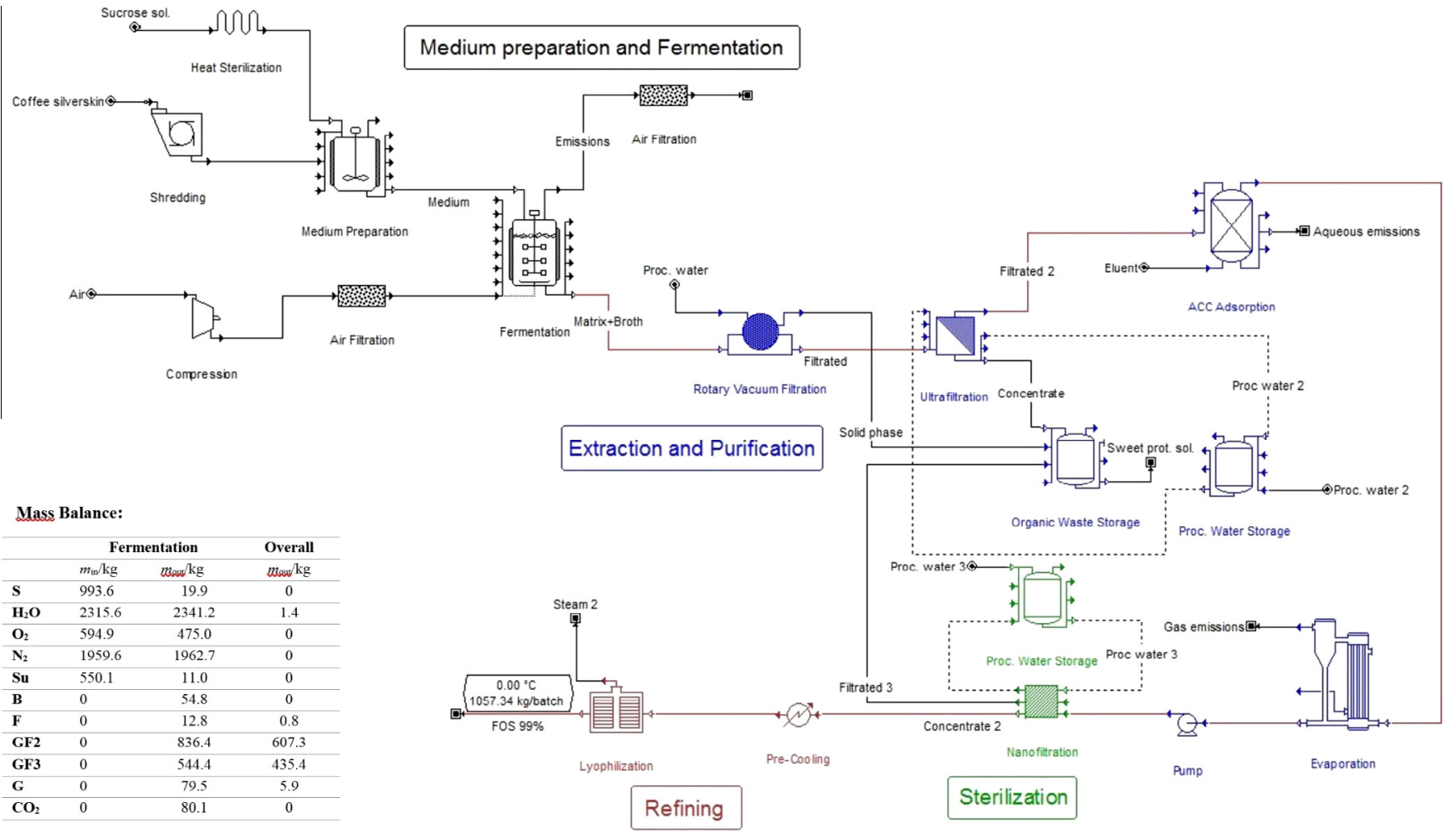

Fig. 3. Process flowchart and mass balance obtained with SuperPro Designer v8.5 for the SSF process (solid-state fermentation). S: sucrose; B: biomass; F: fructose; G: glucose; GF2, GF3: FOS; Su: support (coffee silverskin). 
carrier (corn cobs). In this section the carrier is subject to the following operations: grinding, boiling, washing and drying.

The medium preparation is made in a $5.3 \mathrm{~m}^{3}$ agitated tank that is fed by two streams: the 'Nutrients' stream and the 'Water' stream. The output stream, 'Medium' is sterilized at $121^{\circ} \mathrm{C}$ and sent to an agitated fermenter of $5.4 \mathrm{~m}^{3}$ that also receives a $0.5 \mathrm{~min}^{-1}$ aeration stream, as in the FCF case. The fermentation process occurs during $21 \mathrm{~h}$, at $28^{\circ} \mathrm{C}$ (Mussatto et al., 2009). Two output streams exit the fermenter: the 'Emissions' stream, regarding the gas emissions, and the 'Fermented broth' stream. At the end of the reaction, successive washings are performed similarly to the FCF process. The fermented broth is then centrifuged during $6 \mathrm{~h}$, being the biomass separated from the broth and then recycled to the fermenter $-1.7 \%(w / w)$ of FOS is lost in this operation. The 'Supernatant' stream is taken to the ultrafiltration step to separate residual biomass and yeast extract that was not consumed - an efficiency of FOS recovery of $98.1 \%(w / w)$ is obtained. Two output streams exit the ultrafiltration operation: the 'Filtrate' stream goes to the ACC Adsorption step, which operates similarly as in the FCF case - the specific recovery efficiencies are the same as in the FCF case, giving a global efficiency recovery of FOS of $88.4 \%(w / w)$. However, in this case, the 'Aqueous emissions' stream leaves the operation unit at $40.9{ }^{\circ} \mathrm{C}$ and is cooled until $25.0^{\circ} \mathrm{C}$. The following downstream processes, namely evaporation, nanofiltration (with a $87.2 \%(w / w)$ efficiency of FOS recovery) and lyophilisation operate in the same way as in the FCF process.

\subsubsection{Solid-state fermentation (SSF)}

In the SSF process, the medium is prepared in a $3.8 \mathrm{~m}^{3}$ tank that receives two streams: a previously shredded coffee silverskin stream, which is firstly autoclaved $\left(121^{\circ} \mathrm{C}\right)$ inside the tank in the adequate stoichiometric proportions and, after this, a previously sterilized $\left(112{ }^{\circ} \mathrm{C}\right)$ sucrose solution that is not only used as carbon source, but also as a moistening agent to establish the desired moistening content of 60\% (Mussatto et al., 2013a). The medium is then distributed by 32 trays with a $5 \mathrm{~cm}$ height, by manual operation, and then placed inside the tray bioreactor. The fermenter receives an aeration stream and the 'Medium' stream so the fermentation process occurs for $20 \mathrm{~h}$ at $26^{\circ} \mathrm{C}$ (Mussatto et al., 2013a). At the end of the reaction, successive washings are performed similarly to the other fermentation processes.

It should be noted that the SuperPro Designer v8.5 software does not include appropriate specific unit procedure for solid-state fermentation processes. Therefore, an existent fermenter was selected and the SSF conditions in a tray bioreactor were simulated, namely the lack of agitation, the moistening content and the aeration rate of $0.5 \mathrm{~min}^{-1}$ (Mussatto et al., 2013a; Mitchell et al., 2006). The main parameters adopted in the tray bioreactor fermenter design included the substrate bed height $(0.05 \mathrm{~m})$, the gap between trays $(0.1 \mathrm{~m})$, the number of trays (32) and the fermenter volume $\left(12.39 \mathrm{~m}^{3}\right)$ that would be actually necessary. The substrate bed height that optimizes the process is from $5 \mathrm{~cm}$ to $15 \mathrm{~cm}$ (Ali and Zulkali, 2011). A bed height of $5 \mathrm{~cm}$ was selected as well as a gap between trays of $10 \mathrm{~cm}$. The number of trays was determined by dividing the fermenter working volume (calculated previously and being $\left.4.13 \mathrm{~m}^{3}\right)$ by the volume of a tray $\left(0.129 \mathrm{~m}^{3}\right)$.

Two streams leave the fermenter: the 'Emissions' stream, that corresponds to the gas emissions from the fermentative process, and the 'Matrix + Broth' stream, which is composed by the fermented broth and the remaining amount of the support and nutritional matrix. The extraction stage, which was done using a rotary vacuum filtration operation, takes place in this process and does not take place in the FCF and ICF cases since, in the SSF, the broth is in an almost-solid state and the separation between the liquid phase, from the solid phase, is required. To moisten the medium and to help displacing the sugars to the liquid phase, a $1.5 \%(V / V)$ fraction of water is added (Mussatto et al., 2013a). In this case, for a working volume of $4.14 \mathrm{~m}^{3}, 63.69 \mathrm{~L}$ of water are added. The filtered stream is the main stream and follows to the ultrafiltration step - in this operation the efficiency of FOS recovery is $98.3 \%$ $(w / w)$. The 'Solid phase' stream is sent to the organic waste storage tank and it will be a part of a sweet protein solution, providing additional revenues, as in the precedent fermentation processes.

The subsequent operations take place similarly to the other fermentation processes and are performed in the same way. However, a specific property that differs from the other cases is the temperature of the 'Aqueous emissions' stream $\left(27.1^{\circ} \mathrm{C}\right)$ from the ACC Adsorption, which does not need to be cooled in order to be discharged. In this operation, the global efficiency of FOS recovery equals $88.3 \%(w / w)$. In the nanofiltration step, the efficiency of FOS recovery is $87.0 \%(w / w)$.

\subsubsection{Energy and utilities consumption}

The annual energy and utilities (steam, cooling water and chilled water) global requirements for the FCF, ICF and SSF processes are summarized in Table 3.

\subsection{Cost estimation}

In cost estimations, direct fixed capital cost, labour cost, raw materials cost, consumables cost, waste treatment/disposal cost, utilities cost and global annual operating cost were considered. The materials cost as well as the respective suppliers are presented in Table 4. For the waste treatment/disposal, the cost was set to $0.01 € / t$ (Akiyama et al., 2003). Other costs including equipmentdependent, labour, utilities, consumables and other facility-dependent costs were present in the SuperPro Designer v8.5 database, updated to the year 2014. Regarding the utilities prices, the software defined them as $0.07 € / \mathrm{kWh}$ for standard power, $8.406 € /$ t for steam, $0.035 € /$ t for cooling water and $0.28 € / \mathrm{t}$ for chilled water. The exception is the tray bioreactor in the SSF fermentation that, as mentioned before, is not included in the software's database. Therefore, the results obtained by Castilho et al. (2000) were used to estimate the tray bioreactor equipment cost for the fermentation volume used in this work.

\subsection{Environmental assessment}

The environmental assessment was divided into three categories: environmental load, environmental impact potential and carbon footprint.

\subsubsection{Environment load}

The environment load was determined by taking into account the steps that generate relevant emissions during the processes, namely, the fermentation, corresponding to the $\mathrm{CO}_{2}$ emissions, the adsorption with activated charcoal column, corresponding to the aqueous stream emission, and the evaporation, corresponding to the ethanol gas stream emission. The drying and lyophilisation operations generate water vapour, thus they were not considered in this evaluation.

Table 3

Annual global energy $(E)$ and utilities - steam $(S)$, cooling water $(C W)$ and chilled water $(C h W)$ - requirements regarding the three fermentation processes.

\begin{tabular}{lllll}
\hline & $E(\mathrm{kWh})$ & $S(\mathrm{t})$ & $C W(\mathrm{t})$ & $C h W(\mathrm{t})$ \\
\hline FCF & 211,720 & 327 & 6040 & 15,927 \\
ICF & 170,888 & 321 & 4668 & 13,101 \\
SSF & 126,732 & 393 & 3717 & 11,961 \\
\hline
\end{tabular}

FCF: submerged fermentation of sucrose solution by Aspergillus japonicus using free cells; ICF: submerged fermentation of sucrose solution by A. japonicus using immobilized cells; SSF: solid-state fermentation. 
Table 4

Prices of materials $(P)$ and respective suppliers/sources.

\begin{tabular}{|c|c|c|c|}
\hline Materials & $P(€ / \mathrm{kg})$ & Suppliers & Sources \\
\hline $\mathrm{H}_{3} \mathrm{PO}_{4}$ & 0.63 & Heze Development Zone Dayuan Chemical Co., Ltd. & Made-in-China.com (2014) \\
\hline $\mathrm{NaOH}$ & 0.29 & Tian Jin Shi Jin Hong Wei Bang Chemical Co., Ltd. & Made-in-China.com (2014) \\
\hline Ethanol & $0.40 € / L$ & Cepea - Centre of Advanced Studies in Applied Economy & Cepea (2014) \\
\hline Yeast extract & 1.54 & Dingtao County Anji Fuqiang Yeast Co., Ltd. & Alibaba.com (2014) \\
\hline $\mathrm{NaNO}_{3}$ & 0.33 & Shandong Hailan Chemical Industry Co., Ltd. & Alibaba.com (2014) \\
\hline $\mathrm{KCl}$ & 0.33 & Hebei Lvwang Ecological Fertilizer Co., Ltd. & Alibaba.com (2014) \\
\hline $\mathrm{K}_{2} \mathrm{HPO}_{4}$ & 1.29 & Xiamen Vastland Chemical Co., Ltd. & Alibaba.com (2014) \\
\hline $\mathrm{MgSO}_{4}$ & 0.07 & Dalian CR Science Development Co., Ltd. & Alibaba.com (2014) \\
\hline Water & $0.91^{\mathrm{a}} / 0.94$ & Agere, Portugal & Agere (2014) \\
\hline
\end{tabular}

a Price related to submerged fermentations whereas in the SSF process the price becomes $0.94 € / \mathrm{kg}$.

\subsubsection{Environmental impact potential assessment}

Waste Reduction Algorithm (WAR GUI 1.0) was used for the calculation of the Potential Environmental Impact (PEI), focused on a pollution balance generated during a chemical or biochemical process. The PEI of a specific amount of material or energy can be defined as the effect on the environment if they were randomly discharged. Despite the fact that it cannot be directly measured, the PEI can be estimated through measurable quantities or indicators (Mussatto et al., 2013b). The software requires information about the chemicals used, streams classification and composition (inlet, outlet, product or waste) and energy consumed in the process. It provides the possibility to tweak the specific weights of each environmental category regarding the global environmental impact. However, this environmental assessment is confined only to the processing facility.

There are eight environmental impact categories the software is able to quantify, which can be divided in two main areas: atmospheric and toxicological. The atmospheric impact is subdivided in global warming potential (GWP), ozone depletion potential (ODP), acidification potential (AP) and photochemical oxidation potential (PCOP). Regarding the toxicological impact, it has human toxicity by dermal exposition or inhalation (HTPE), human toxicity by ingestion (HTPI), aquatic toxicity potential (ATP) and terrestrial toxicity potential (TTP). From the weighted sum of every impact indicators, the global impact indicator, by $\mathrm{kg}$ of product, can be obtained (Mussatto et al., 2013b).

Summarizing, the smaller the PEI indicator of the process, the more favourable it is for the environment. Thus, it is possible, through the results, to develop the environmental sustainability of a process, modifying it, in order to try and decrease its environmental impact potential (Mussatto et al., 2013b).

\subsubsection{Carbon footprint}

Carbon footprint is associated to the consumption of fossil energy in the processing stage (Mussatto et al., 2013b). Under the scope of this work, the energy from the power grid and the requirements for steam generation were considered. The equivalence factor of $1 \mathrm{kWh}$ giving $0.446 \mathrm{~kg}$ of $\mathrm{CO}_{2 \mathrm{e}}\left(\mathrm{CO}_{2}\right.$ equivalent) was used (Carbon Trust, 2013).

\section{Results and discussion}

\subsection{FOS productivity}

The purity and annual productivity obtained for the three processes are presented in Table 1. SSF is the only process that achieves the previously proposed annual productivity of $200 \mathrm{t}$, with an annual productivity of $232.6 \mathrm{t}$ while FCF and ICF achieve $148.9 \mathrm{t}$ and $158.3 \mathrm{t}$, respectively. In addition, the SSF process presents a more concentrated product, with $98.6 \%(w / w)$ purity against $96.6 \%(w / w)$ and $98.4 \%(w / w)$ for the FCF and ICF, respectively.

After the fermentation stage, FOS concentration in each process is $210.9 \mathrm{~g} / \mathrm{L}$ (FCF), $245.7 \mathrm{~g} / \mathrm{L}$ (ICF) and $403.7 \mathrm{~g} / \mathrm{L}$ (SSF). This means that the FOS concentration in the SSF process is 1.64 and 1.91 times greater than the FOS concentration in the ICF and FCF processes, respectively. This difference is partly explained by the lower water content of the "Medium" stream entering the fermentation stage in the SSF, comparatively to ICF and FCF. In the SSF, the inlet stream contains $2315.6 \mathrm{~kg}$ of water whereas in the ICF and FCF it contains $3645.0 \mathrm{~kg}$ and $4185.0 \mathrm{~kg}$, respectively. Here resides one important advantage of the SSF compared to FCF and ICF: lower water content in and out and, with this, greater the product concentration and lower the wastewater generation.

Regarding the FOS/S coefficients, in stoichiometric calculations and regarding, for instance, only GF2 product $\left(\mathrm{GF} 2 / \mathrm{S}=c_{\mathrm{GF} 2} / c_{\mathrm{S}}\right.$, being $c_{i}$ the coefficient of the component $i$ ), the ratio is 1.12 times higher in SSF than in ICF and 1.29 times higher than in FCF. After software simulation, this ratio gives 1.12 and 1.28 times higher than in ICF and FCF, respectively, confirming the previous stoichiometric estimations.

Mass balances, per batch, are presented in Figs. 1-3. These balances are presented for the Fermentation stage and for the overall process. The latter considers all the input streams for the fermentation stage, however, it considers only the final product stream as being the output stream. Hence, the difference in output-input of one same component represents the losses and/or storage stages which it went through.

It should be noticed that the SSF not only produces greater quantities of FOS with higher purity, but also produces greater amounts of the shorter chain FOS (GF2 and GF3), which have more prebiotic activity and stronger sweetness (Yun, 1996). This can be observed in the Fig. 4 where the composition of the final stream,

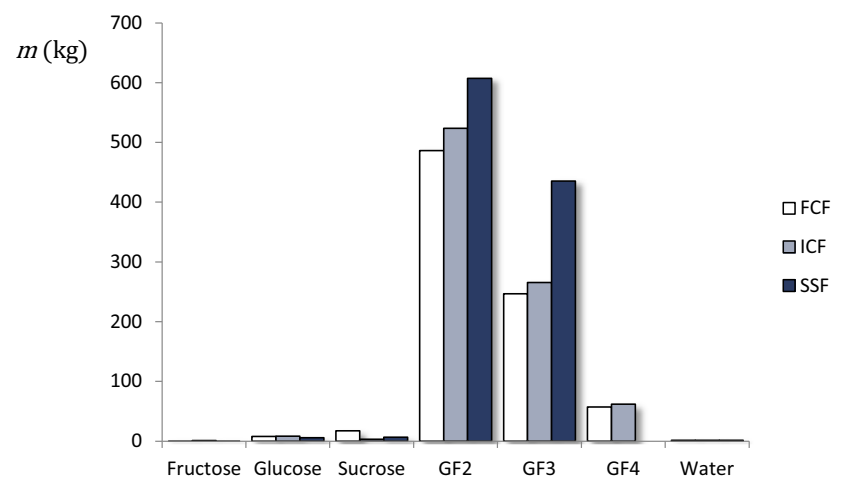

Fig. 4. Composition of the final product streams, expressed in mass per batch $(m)$ relatively to the FCF, ICF and SSF processes. 
per batch and for each process, is presented. SSF produces $607.3 \mathrm{~kg}$ of GF2 and $435.4 \mathrm{~kg}$ of GF3 while the FCF and ICF processes produce GF4 (57.4 kg and $61.85 \mathrm{~kg}$, respectively) and significantly less GF2 (486.5 kg and $523.5 \mathrm{~kg}$, respectively) and GF3 (246.6 kg and $265.4 \mathrm{~kg}$, respectively).

Productivity values, expressed in mass per unit volume per hour, are $8.79 \mathrm{~g} / \mathrm{L} \mathrm{h}, 11.7 \mathrm{~g} / \mathrm{L} \mathrm{h}$, and $20.2 \mathrm{~g} / \mathrm{L} \mathrm{h}$ in FCF, ICF and SSF, respectively. This is the result of not only a greater concentration in the outlet stream of the SSF, but also a lower fermentation time required for this process (SSF: $20 \mathrm{~h}$; ICF: $21 \mathrm{~h}$; FCF: $24 \mathrm{~h}$ ).

\subsection{Economic evaluation}

The direct fixed capital cost (DFCC) is $11.7 \mathrm{M} €, 12.4 \mathrm{M} €$ and 10.6 M $€$ for the FCF, ICF and SSF, respectively (Fig. 5a). The total plant direct cost (TPDC), involving equipment, installation, process piping, instrumentation, insulation, electrical, buildings, yard improvement and auxiliary facilities costs, represents the greater contribution for this investment (6.4 M€, 6.8 M€ and 5.8 M€ for the FCF, ICF and SSF, respectively).

(a)

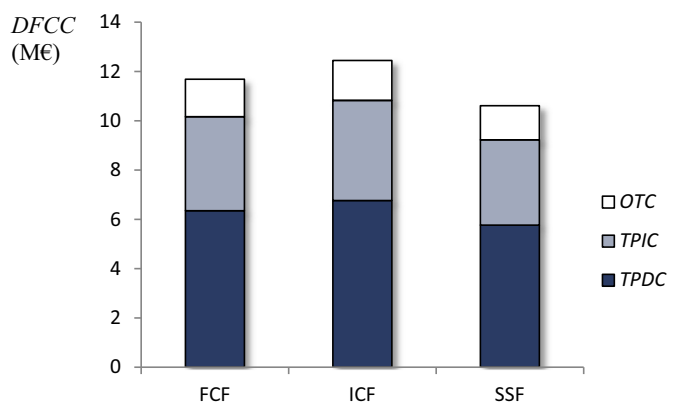

(b)

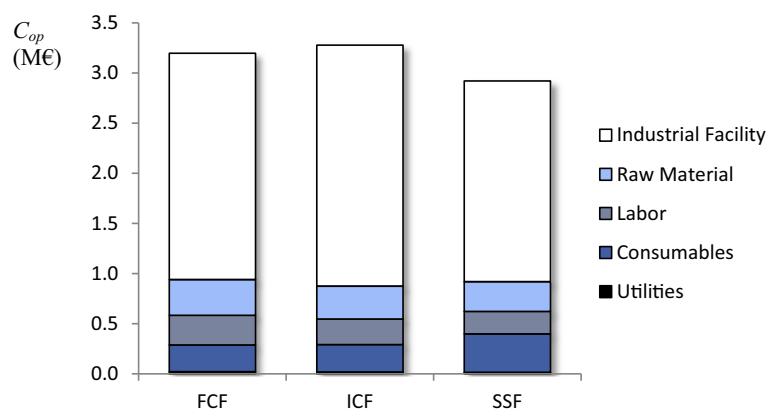

(c)

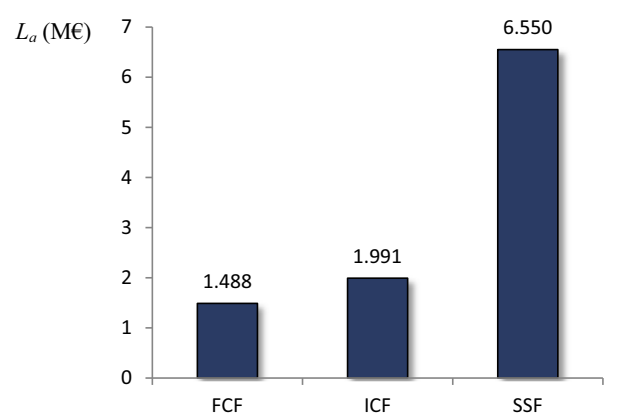

Fig. 5. (a) Direct fixed capital cost $(D F C C)$, which includes the total plant direct cost $(T P D C)$, the total plant indirect cost (TPIC) and other costs (OTC), like contractor's fee and contingencies, for the three fermentation processes; (b) annual operating costs, $C_{\text {op }}$ (prices for 2014), and contributions of the 'Industrial Facility', 'Raw Materials', Labor', 'Consumables' and 'Utilities' sections, obtained in SuperPro Designer v8.5 for the three fermentation processes; (c) annual profit, $L_{\mathrm{a}}$, for the three fermentation processes.
Information about equipment cost $\left(C_{\mathrm{e}}\right)$ is presented in Table 5. The fermenter represents the highest equipment investment for FCF and ICF (588,000 $€$ and 576,000 $€$, respectively), whereas for the SSF, the tray bioreactor represents one of the minimum costs $(22,000 €)$. In the ICF process there are two blending tanks used in both Medium Preparation (Fermentation) and Boiling (Immobilization Carrier Preparation) stages.

The total plant indirect cost (TPIC), which is the sum of the engineering and construction costs, are 3.8 M€, 4.1 M€, and 3.5 M€ for FCF, ICF and SSF, respectively; while other costs (OTC) involve the contractor's fee and contingencies and are $1.5 \mathrm{M} €, 1.6 \mathrm{M} €$, and 1.4 M€, for FCF, ICF and SSF, respectively. The total capital investment (TCI) for each project results from the sum of the DFCC with the working capital and the start-up cost. For the FCF process the TCI is $12.3 \mathrm{M} €$ whereas for the ICF and SSF the TCI equals $13.1 \mathrm{M} €$ and $11.2 \mathrm{M} €$, respectively.

Fig. $5 \mathrm{~b}$ shows the contributions of each section for the operating costs $\left(C_{\mathrm{op}}\right)$, as well as the total cost, for each fermentation process. As can be seen, the operating costs, expressed in an annual basis, are the highest in the case of ICF (3.3 M€) and are the lowest in the case of the SSF $(2.9 \mathrm{M} €)$. Portions with higher contribution to the global operating costs are, in the three cases, due to the industrial facility costs, with $71 \%$ of the total operating costs in the case of FCF, $73 \%$ in the case of ICF and 69\% in the case of SSF. However, in terms of consumables, the SSF process is the one with the highest annual cost $(0.38 \mathrm{M} €)$, which is explained by the fact that this process has a shorter cycle time compared to other processes, which means that there is a greater number of cycles per year, and therefore a greater number of adsorbent replacements in the adsorption step with activated charcoal column (main contributor to the cost of consumables). The replacement rate of this material

Table 5

Equipment $\operatorname{cost}\left(C_{\mathrm{e}}\right)$, consumables annual cost $\left(C_{\mathrm{ac}}\right)$, and economic parameters for the three fermentation processes. Return on investment $(R I)$, payback time $(P B)$, internal rate of return (IRR) and net present value (NPV) for a 7\% interest rate.

\begin{tabular}{|c|c|c|c|}
\hline & FCF & ICF & SSF \\
\hline Equipment/unit process & $C_{e}(k €)$ & & \\
\hline Fermenter & 588 & 576 & 22 \\
\hline Centrifugal compressor & 51 & 51 & 51 \\
\hline Air filter & 5 & 5 & 5 \\
\hline \multirow{2}{*}{ Blending tank } & 174 & 170 & 162 \\
\hline & & 103 & \\
\hline Storage tank & 35 & 35 & 35 \\
\hline Centrifuge & 218 & 204 & - \\
\hline Ultrafiltration & 83 & 81 & 71 \\
\hline Activated charcoal column & 190 & 192 & 205 \\
\hline Evaporator & 77 & 77 & 77 \\
\hline Nanofiltration & 15 & 19 & 19 \\
\hline Freeze dryer/lyophilisation & 372 & 372 & 372 \\
\hline Heat exchanger & 230 & 220 & 192 \\
\hline Heat sterilizer & 230 & 220 & 192 \\
\hline Centrifugal pump & 7 & 7 & 7 \\
\hline Shredder & - & 52 & 55 \\
\hline Drying tank & - & 22 & - \\
\hline Vacuum filtration & - & - & 71 \\
\hline Unlisted equipment & 236 & 251 & 355 \\
\hline Consumable & $C_{a c}(k €)$ & & \\
\hline Dft membrane (ultrafiltration) & 12.0 & 11.5 & 10.7 \\
\hline Dft GAC packing (activated charcoal column) & 235.0 & 245.4 & 352.7 \\
\hline UF membrane (nanofiltration) & 19.5 & 16.5 & 19.8 \\
\hline \multicolumn{4}{|l|}{ Economic parameters } \\
\hline$R I(\%)$ & 16.25 & 18.11 & 44.13 \\
\hline$P B$ (year) & 6.16 & 5.52 & 2.27 \\
\hline $\operatorname{IRR}(\%)$ & 9.61 & 11.64 & 33.36 \\
\hline$N P V(\mathrm{M} €)$ & 1.93 & 3.85 & 24.22 \\
\hline
\end{tabular}

FCF: submerged fermentation of sucrose solution by Aspergillus japonicus using free cells; ICF: submerged fermentation of sucrose solution by A. japonicus using immobilized cells; SSF: solid-state fermentation. 
is the same in all three cases, occurring every 10 fermentation cycles. The FCF operates at 182 cycles per year; the ICF operates at 183 cycles per year, while the SSF operates at 220 cycles per year. Regarding the raw materials costs it is important to note that, due to the fact that the coffee silverskin provides a nutritional source to the SSF, this process does not demand acquisition of micronutrients, requiring lower investments at this level. The sweet protein solution stream, stored in the tank for organic waste, and providing additional revenues, supplies $74 \%$ of labour costs in the case of FCF and SSF and $49 \%$ in the case of ICF.

When compared to the other processes, SSF presents a large economic advantage (Fig. 5c), achieving annual revenues of 9.47 M€, more than the double when compared to FCF (102\% more) and $80 \%$ more than the ICF process. The profit margin per $\mathrm{kg}$ of FOS produced, obtained in the three cases is $10.00 € / \mathrm{kg}$ in the case of the FCF, $12.58 € / \mathrm{kg}$ for the ICF and $28.16 € / \mathrm{kg}$ for the SSF process.

Important economic parameters such as the return on investment $(R I)$, the payback time $(P B)$, the internal rate of return (IRR) and the net present value (NPV), for the three fermentation processes, are summarized in Table 5 . It can be realized that the three processes are economically feasible, since the NPV is positive and the IRR is higher than the interest rate applied (7\%) (Oliveira and Fernandes, 2011) for the three cases. However, it should be noted that the SSF process provides the best results since it has the highest percentage of return on investment (44.13\%) and a value of payback time of 2.27 years, against 5.52 years for the ICF and 6.16 years for the FCF.

\subsection{Environmental assessment}

As previously stated, the environmental assessment was divided into three categories: environmental load, environmental impact potential and carbon footprint.

\subsubsection{Environmental load}

In this section, the mass emissions that generate environmental load are presented. In Table 6 these emissions can be observed, per batch, where $m_{i}$ represents the mass of the stream and $i$ represents the total stream when no additional information is provided (evaporation and adsorption operation cases). The process with the highest $\mathrm{CO}_{2}$ emissions due to the fermentation operation is the FCF $(148.7 \mathrm{~kg}$ ) whereas the ICF has the lowest value $(64.9 \mathrm{~kg})$. Regarding to the $\mathrm{CO}_{2} / \mathrm{FOS}$ mass ratios, in the FCF this value is more than two times higher relatively to ICF (2.37 times higher) and SSF (2.32 times higher) cases. Comparing these values to the stoichiometric coefficients previously estimated by the SuperPro Designer simulation, the $\mathrm{CO}_{2} / \mathrm{FOS}$ ratio in the FCF is 2.35 times higher than the ICF and 2.32 times higher than the SSF. These values (stoichiometric estimation and simulation) are concordant. As the extent of $\mathrm{CO}_{2}$ production indirectly reflects biomass development (Roussos et al, 1997), it would be expected that FCF, which has a coefficient

\section{Table 6}

Mass emissions $\left(m_{i}\right)$ from the fermentation, adsorption with activated charcoal column and evaporation steps ( $i$ represents the total stream when no additional information is provided).

\begin{tabular}{llll}
\hline & $m_{i}(\mathrm{~kg})$ & & \\
\cline { 2 - 4 } & $\begin{array}{l}\text { Fermentation } \\
\left(i=\mathrm{CO}_{2}\right)\end{array}$ & Adsorption & Evaporation \\
\hline FCF & 148.7 & 3819 & 2056 \\
ICF & 64.9 & 3582 & 2056 \\
SSF & 80.1 & 2525 & 2056 \\
\hline
\end{tabular}

FCF: submerged fermentation of sucrose solution by Aspergillus japonicus using free cells; ICF: submerged fermentation of sucrose solution by A. japonicus using immobilized cells; SSF: solid-state fermentation. for biomass of 1.05 , had a $\mathrm{CO}_{2}$ coefficient higher than ICF and SSF (assuming FOS production in each case would not vary in such a way it'd change this ratio behaviour), which have biomass coefficients of 0.51 and 0.78 , respectively. The $\mathrm{CO}_{2}$ stoichiometric coefficients for FCF, ICF and SSF are 1.09, 0.52 and 0.64 , respectively. To explain the differences between $\mathrm{CO}_{2}$ productions in each fermentation process, a different kind of study would be necessary. For instance, a laboratory study regarding biomass development, $\mathrm{CO}_{2}$ production and enzyme activity would be adequate and would possibly return more conclusive results in this regard.

The same can be said relatively to $\mathrm{CO}_{2} / \mathrm{O}_{2}$ ratio. In stoichiometric calculations this ratio is 3.32 times higher in FCF than in ICF and 2.44 times higher than in SSF. After software simulation, $\mathrm{CO}_{2} / \mathrm{O}_{2}$ is 3.36 times higher in FCF than in ICF and 2.45 times higher than in SSF. Again, biomass coefficients (and so, biomass production) may explain the differences in each fermentation case.

The FCF generates the greatest aqueous emission in the adsorption with activated charcoal column $(3819 \mathrm{~kg})$ while the SSF process generates the lowest amount $(2525 \mathrm{~kg})$. The lower quantities of water used in the SSF process contribute to this value, resulting in lower wastewater generation. The evaporation step originates the same environmental load in the three processes $(2056 \mathrm{~kg})$ in which $67 \%$ of the total stream is ethanol.

On another topic, integrated mass, minimization and reutilization of wastewater concepts were present in the design of these processes. Therefore, the water was a target of special attention regarding these aspects. In the three processes the process water used in the ultrafiltration and nanofiltration steps was reutilized. With this, $600 \mathrm{t}$ of water are saved annually in the FCF process whereas $580 \mathrm{t}$ and $560 \mathrm{t}$ are saved in the ICF and SSF, respectively. It should be noticed that, in the ICF process, the immobilized biomass is recycled to the fermenter after centrifugation. The organic residues that come from the centrifugation, vacuum filtration, ultrafiltration and nanofiltration steps are stored in a tank. This sweet protein solution generates an additional economic profit as it is sold to the animal feed industry for a price of $0.75 € / \mathrm{kg}$.

In order to establish a continuous environmental improvement of these processes, some additional measures are proposed. The emission stream from the adsorption step could be redirected to the organic residues tank as it contains only sugars (fructose, sucrose, glucose, FOS and water). Despite this possibility, this stream is strongly diluted (92-95\% of water, depending on the fermentation process), which means that it would neither provide important additional revenues nor an important pollution factor. The outlet gas stream from the evaporation step, containing ethanol and water, could be reutilized in the adsorption with activated charcoal column as eluent or even concentrated in an additional subsequent operation unit and eventually sold to the chemical industry.

\subsubsection{Environmental impact assessment}

The environmental impact assessment was made recurring to the software WAR. Fig. 6 reveals the PEI indicators (I), expressed per mass of FOS produced, relatively to each impact category, as well as the sum of these indicators, resulting in the global PEI for each fermentation process. The global PEI indicator has the highest value for the ICF with $0.751 \mathrm{~kg}^{-1}$ while the lowest value is presented by the SSF process with $0.395 \mathrm{~kg}^{-1}$. The photochemical oxidation category is the one that contributes the most for the global PEI in the three processes with $0.265 \mathrm{~kg}^{-1}, 0.362 \mathrm{~kg}^{-1}$ and $0.313 \mathrm{~kg}^{-1}$ for the FCF, ICF and SSF, respectively. The aquatic toxicity potential, global warming potential and ozone depletion potential are the categories with less contribution for the global PEI. 


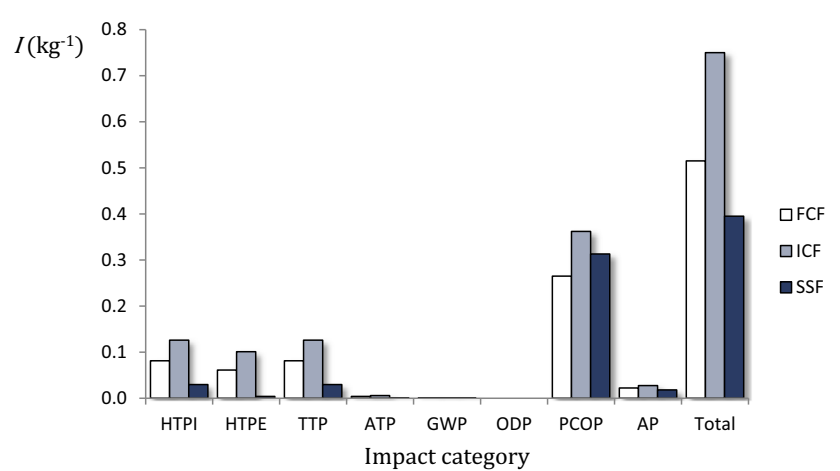

Fig. 6. Values of environmental impact potential indicators ( $I$ ), expressed per mass of FOS produced, calculated by the software WAR relatively to each impact category, for each fermentation process. Human toxicity by ingestion (HTPI), human toxicity by dermal exposition or inhalation (HTPE), terrestrial toxicity potential (TTP), aquatic toxicity potential (ATP), global warming potential (GWP), ozone depletion potential (ODP), photochemical oxidation potential (PCOP) and acidification potential (AP).

\subsubsection{Carbon footprint}

The carbon footprint $(C F)$ was determined as the mass of $\mathrm{CO}_{2}$ equivalent per mass of FOS produced dependent on the energy consumption from the power grid and due to steam generation for heat exchanging purposes. The conversion factor used was $1 \mathrm{kWh}$ giving $0.4465 \mathrm{~kg}$ of $\mathrm{CO}_{2 \mathrm{e}}$ (Carbon Trust, 2013). SSF presented a $C F$ of $0.728 \mathrm{~kg} / \mathrm{kg}$ whereas FCF and ICF presented a $C F$ of $1.365 \mathrm{~kg} / \mathrm{kg}$ and $1.169 \mathrm{~kg} / \mathrm{kg}$, respectively. It can be concluded that SSF is environmentally more favourable than the other processes whereas FCF is the least favourable.

\section{Conclusion}

Given the present results, it can be concluded that the three processes are economically feasible. However, the SSF process has the highest potential to be implemented on an industrial scale, providing a higher productivity (it is the only process that reaches, and overcomes, the initial goal of producing $200 \mathrm{t}$ of FOS per year), a more concentrated product, more economic profits with a much shorter payback time, and it is also a more environmentally friendly process, not only with less global environmental impact potential but also with a lower carbon footprint and less wastewater generation.

\section{References}

Agere - Empresa de Aguas, Efluentes e Resíduos de Braga, 2014. Water Tariff Available online at: <http://www.agere.pt/web1/zp/tpl1/id1/paginas/ficha.asp? p_case=2\&p_cod_elemento=91> (accessed 27-Jul-2014).

Akiyama, M., Tsuge, T., Doi, Y., 2003. Environmental life cycle comparison of polyhydroxyalkanoates produced from renewable carbon resources by bacterial fermentation. Polym. Degrad. Stab. 80, 183-194.

Ali, H.Kh.Q., Zulkali, M.M.D., 2011. Design aspects of bioreactors for solid-state fermentation: a review. Chem. Biochem. Eng. Q. 25, 255-266.

Alibaba.com. International Prices, 2014. Available online at: <http://www. alibaba.com/> (accessed 27-Jul-2014).

Carbon Trust, 2013. Conversion factors - Energy and carbon conversions. Available online at: <http://www.carbontrust.com/> (accessed 27-Jul-2014).

Castilho, L.R., Polato, C.M.S., Baruque, E.A., Sant'Anna Jr., G.L., Freire, D.M.G., 2000. Economic analysis of lipase production by Penicillium restrictum in solid-state and submerged fermentations. Biochem. Eng. J. 4, 239-247.

Cepea - Centro de Estudos Avançados em Economia Aplicada - ESALQ/USP, 2014. Hydrated Ethanol Prices. Available online at: <http://cepea.esalq.usp.br/etanol/> (accessed 27-Jul-2014).

Gonçalves, C., 2011. Fructo-oligosaccharides Recovery from Fermentation Processes (Ph.D. thesis). Universidade do Minho, Portugal.

Made-in-China.com, 2014. China Manufacturers and Suppliers Prices. Available online at: <http://www.made-in-china.com> (accessed: 27-Jul-2014)

Martins, S., Mussatto, S.I., Martínez-Avila, G., Montañez-Saenz, J., Aguilar, C.N., Teixeira, J.A., 2011. Bioactive phenolic compounds: production and extraction by solid-state fermentation. A review. Biotechnol. Adv. 29, 365-373.

Mitchell, D.A., Krieger, N., Berovič, M., 2006. Solid-State Fermentation Bioreactors. Fundamentals of Design and Operation. Springer, Berlin.

Monsan, P.F., Ouarné, F., 2009. Oligosaccharides derived from sucrose. In: Charalampopoulos, D., Rastall, R.A. (Eds.), Prebiotics and Probiotics Science and Technology. Springer, New York, pp. 293-336.

Mussatto, S.I., Aguilar, C.N., Rodrigues, L.R., Teixeira, J.A., 2009. Fructooligosaccharides and $\beta$-fructofuranosidase production by Aspergillus japonicus immobilized on lignocellulosic materials. J. Mol. Catal. B Enzym. 59, $76-81$.

Mussatto, S.I., Ballesteros, L.F., Martins, S., Maltos, D.A.F., Aguilar, C.N., Teixeira, J.A., 2013a. Maximization of fructooligosaccharides and $\beta$-fructofuranosidase production by Aspergillus japonicus under solid-state fermentation conditions. Food Bioprocess Technol. 6, 2128-2134.

Mussatto, S.I., Moncada, J., Roberto, I.C., Cardona, C.A., 2013b. Techno-economic analysis for brewer's spent grains use on a biorefinery concept: the Brazilian case. Bioresour. Technol. 148, 302-310.

Mussatto, S.I., Teixeira, J.A., 2010. Increase in the fructooligosaccharides yield and productivity by solid-state fermentation with Aspergillus japonicus using agroindustrial residues as support and nutrient source. Biochem. Eng. J. 53, 154157.

Nobre, C., Teixeira, J.A., Rodrigues, L.R., 2012. Fructo-oligosaccharides purification from a fermentative broth using an activated charcoal column. N. Biotechnol. 29, 395-401.

Oliveira, W.S., Fernandes, A.J., 2011. Economic feasibility applied to wind energy projects. Int. J. Emerg. Sci. 1, 659-681.

Roussos, S., Lonsane, B.K., Raimbault, M., Viniegra-Gonzalez, G., 1997. Advances in Solid State Fermentation. Kluyer Academic Publishers, Dordrecht.

Yun, J.W., 1996. Fructooligosaccharides--occurrence, preparation, and application. Enzyme Microb. Technol. 19, 107-117. 